\title{
EDITORIAL
}

\section{Intracardiac Conduction Intervals: An Electrophysiological Mirror of the Brazilian Population}

\author{
Erivelton A. do Nascimento ${ }^{1,2,3(0)}$
}

Hospital Universitário Antônio Pedro - Universidade Federal Fluminense, ${ }^{1}$ Niterói, RJ - Brazil Instituto Estadual de Cardiologia Aloysio de Castro, ${ }^{2}$ Rio de Janeiro, RJ - Brazil

Complexo Hospitalar de Niterói, ${ }^{3}$ Niterói, $R J$ - Brazil

Editorial referring to the article: Analysis of Conduction Intervals in Normal Electrophysiological Studies: Establishment of Reference Values the Brazilian Population

In the current edition of the International Journal of Cardiovascular Sciences, Leiria et al. ${ }^{1}$ have published a historical cohort of 124 electrophysiological studies considered normal, and evaluated three parameters of intracardiac conduction: (1) PA interval; (2) $\mathrm{AH}$ interval and (3) HV interval. The reference values for baseline electrophysiological parameters in the Brazilian population are of great interest due to their unique characteristics.

Since the description of the electrical potential in the end portion of the atrioventricular (AV) node by, Dandamudi and Vijayaraman ${ }^{2}$ related Wilhelm His Jr., in 1893, which would come to be named the bundle of His, cardiac electrophysiology has added knowledge to both the diagnosis and treatment of the different forms cardiac arrhythmias, and to the field of artificial cardiac stimulation.

With the evolution of the catheters and sheaths used to perform cardiac electrophysiology procedures, the electrophysiological study has increasingly become part of the propedeutics of cardiac arrhythmias and, in some clinical conditions, it can stratify the risk of sudden cardiac death. ${ }^{3}$

For conducting the electrophysiological study, multipolar electrodes catheters are inserted into the cardiac cavity under fluoroscopy guidance through deep venous accesses (more rarely, arterial punctures). These catheters are connected to an electrophysiology polygraph, where both the intracardiac electrical

\section{Keywords}

Cardiac Electrophysiology. Cardiac arrhythmias. Cardiac Electrophysiological Techniques. potentials and the 12-lead surface electrocardiogram are recorded. ${ }^{4}$

The PA interval represents the depolarization time of the right atrium, from the sinus node to the atrioventricular node; the $\mathrm{AH}$ interval reflects the conduction time from the compact AV node to the His bundle and the HV interval represents the conduction time from the onset of the His bundle to the ventricular myocardium, with normal values described in the literature, as follows: 9 to $145 \mathrm{~ms}, 45$ to $140 \mathrm{~ms}$ and 35 to $55 \mathrm{~ms}$, respectively. ${ }^{3,4}$ In this cohort, the authors found: $23 \pm 9 \mathrm{~ms}, 97 \pm 34 \mathrm{~ms}$ and $45 \pm 8 \mathrm{~ms}$ for the PA, AH and HV intervals, respectively.

It is known that several factors can influence electrophysiological parameters, among them, age, sex, sympathetic tone and medication use. In this context, Taneja et al., ${ }^{6}$ conducted the first study to demonstrate that the HV interval is greater in men than in women. ${ }^{6}$ Similarly to the present study, the authors also found larger $\mathrm{AH}$ and $\mathrm{HV}$ intervals in older patients.

The AH interval is strongly related to a patient's autonomic system, and its increased absolute value does not necessarily reflect the function of the AV node, whereas an $\mathrm{HV}$ interval greater than 70 ms may represent infra-Hisian block, associated with a worse prognosis, and the need for a definitive pacemaker implant. ${ }^{7}$

Some aspects deserve consideration: one of them is that the present study reflects the reality of a single center and, in the retrospective analysis of the data, comorbidities and drug use were not evaluated. The presence of structural heart disease, fibrosis of the conduction system, diabetes mellitus, renal failure, metabolic status, among others, can dynamically alter the baseline electrophysiological intervals of patients.

Mailing Address: Erivelton A. do Nascimento

Rua Marquês de Paraná, 303. Postal code: 24033-900, Centro, Niterói, RJ - Brazil.

E-mail: hpcrates7@gmail.com 
Some questions seem certain in the literature: some non-modifiable variables, such as age and gender, influence the electrophysiological parameters of healthy individuals. ${ }^{6}$ Therefore, these variations must be taken into account when carrying out diagnostic and therapeutic electrophysiological studies. In this scenario, electrophysiological maneuvers of programmed atrial and ventricular stimulation can provide better information on the conduction system.

In this sense, the findings of the present study opens opportunities to learn more about the intracardiac conduction intervals in the Brazilian population.

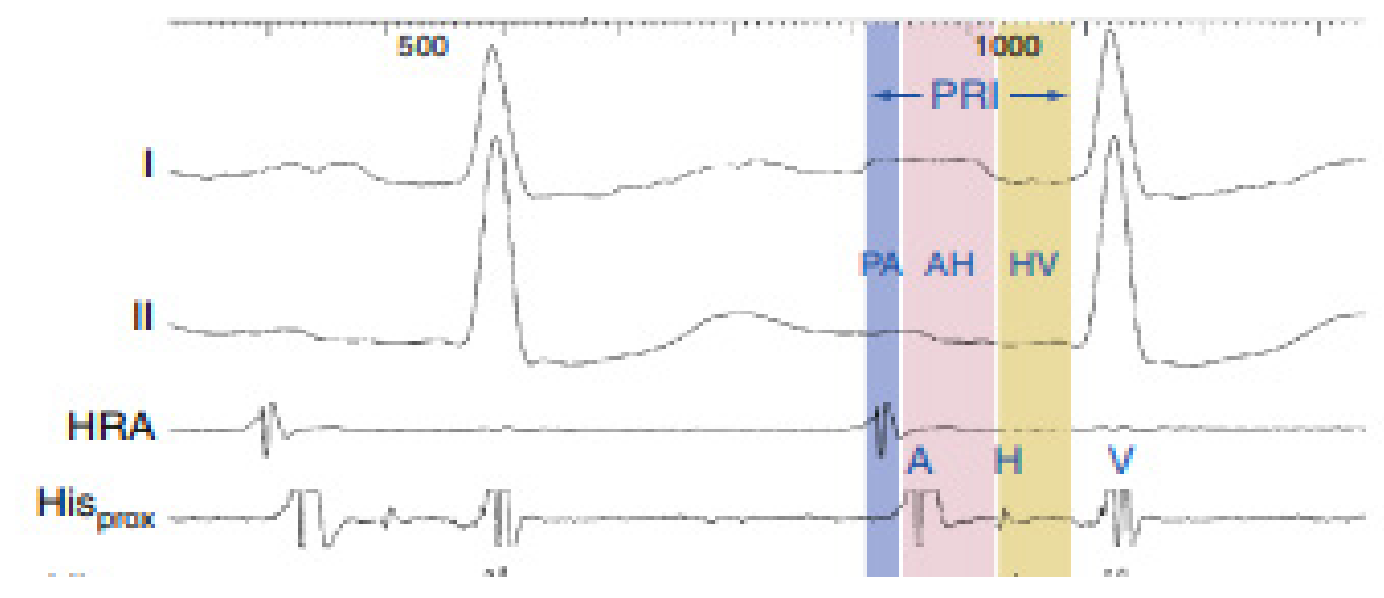

Figure 1 - Association between the surface electrocardiogram and the intracavitary electrical potential:The PA, AH and HV intervals. (Adapted from Zipes et al.) 5 I and II: Peripheral derivations of the surface electrocardiogram; PRI: PR interval; PA: PA interval; AH: AH interval; HV: HV interval; HRA: Electrical potential of the high right atrium; HisProx: Electrical potential of the proximal HIS bundle.

\section{References}

1. Leiria TLL, Santos CBL, Santanna RF, Trombetta JS Osterkamp $\mathrm{G}$, Kruse ML, et al. Analysis of conduction intervals in normal electrophysiological conduction intervals in normal electrophysiological studies: Establishment of reference values the Brazilian population. Int J Cardiovasc Sci. 2020; 33(5):488-494.

2. Dandamudi G, Vijayaraman P. History of His bundle pacing. J Electrocardiol. 2017;50(1):156-60.

3. Hachul, DT et al. Tratado de Arritmias Cardíacas: fisiopatologia, diagnóstico e tratamento. 1 ed. Rio de Janeiro: Atheneu; 2019.
4. Josephson ME. Josephson's Clinical Cardiac Electrophysiology. Philadelphia:Wolters Kluwer Health; 2015.

5. Zipes et al. Clinical Arrhythmology and Electrophysiology. A Companion to Braunwald's Heart Disease. 2 ed. Philadelphia: Elsevier; 2012.

6. Taneja T, Mahnert BW, Passman R, Goldberger J, Kadish A. Effects of sex and age on electrocardiographic and cardiac electrophysiological properties in adults. Pacing Clin Electrophysiol. 2001;24(1):16-21.

7. Maia, IG et al. Eletrofisiologia Clínica e Intervencionista das Arritmias Cardíacas. 1 ed. Rio de Janeiro: Revinter; 1997. 